\title{
Goal Setting as a Motivator for Student Performance: Evidence from Lab Experiments
}

\author{
Sudipta Roy \\ University of St. Francis \\ Bibhas Saha \\ Durham University
}

Can goal-setting motivate college-level students to improve their performance? We report the results of a two-stage study designed to test the effects of performance-based versus action-based goals. We find that performance-based goals are not significantly motivating but action-based goals are. Our equation specifications capture the dynamic interaction between goal setting, attainment, and revision as students are permitted to revise their targets through the semester. We find that the performance trajectory of attainers is different from that of non-attainers. Whether targets were revised, and in which direction, also seems to matter. Our findings have implications for goal-setting interventions targeted towards atrisk students.

\section{INTRODUCTION}

In 2015, the U.S. Department of Education reported that nearly half of all students who begin college do not graduate in six years. The consequences of this for student loan debt has received increasing attention in recent years. Simultaneously, institutions of higher education have introduced newer teaching methods that (i) are expected to boost student success, and (ii) are easily scalable. Some of these include the flipped classroom model (Winquist \& Carlson, 2017; Shinaberger, 2017) and the use of a blended learning format (Hamilton and Tee, 2013). Adopters of these methods have documented the positive impact of the use of innovative teaching methods on student retention and success.

A related line of research has studied the effect of incentives - both financial and non-financial - on student effort. As might be expected, findings vary depending on the type of incentive offered as well as the level of educational attainment at which the incentive is offered.

In a study on primary and high school students, Levitt et. al. (2012) find that incentives framed as losses have a stronger effect on performance compared to awards received upon performance attainment. The researchers find that younger students are motivated more by non-monetary awards such as trophies, while older students are more motivated by financial incentives of the order of $\$ 10-\$ 20$.

Jalava et. al. (2014) studied the impact of non-financial incentives, viz. A-F grading, ranks, certificates and trophies, on sixth graders in Sweden. Highly skilled students are found to exert just as 
much effort with or without incentives, while incentives do not motivate those with lower skill levels. Incentives are found to have the most impact on students in the middle two quartiles.

Financial incentives may not be scalable or sustainable from a budget perspective, nor may the use of such incentives be desirable for college level courses. Similarly, incentives that are non-financial for students may still impose a financial cost on the awarding institution. Furthermore, college students may be motivated by factors different from those that motivate middle school students. At the college level, therefore, a more desirable approach to motivating students might be to use goal setting without added incentives. The incentive or reward in this case is the grade that a student earns (or receives) on completion of the course. Since our study participants are college level students, review of earlier work on this student demographic is informative.

The effect of goal setting, even when narrowed down to the population of college students, can vary by classroom environment (whether the course is introductory or advanced, size of classroom) how learning is assessed (a variety of assessments or only multiple-choice exams), and grading criteria (whether course grades are based on a curve). Barron \& Harackiewicz $(2001,2003)$ argue, for instance, that performance-based goals may be consistent with introductory large classes in which performance is assessed based on multiple-choice exams and grades are curved. Mastery learning, on the other hand, may be better aligned with advanced courses that use a variety of assessments for performance evaluation. Their empirical studies distinguish between mastery, performance, and work avoidance approaches. The authors find that the relationship between goals and outcomes are qualitatively similar in both introductory and advanced courses. While this is contrary to what the authors had expected, it suggests that performance-based goals can positively affect outcomes at any level. Another interesting finding of the authors' research is that mastery goals are positively linked to interest in the course.

Schippers et. al. (2015) find a positive impact of a goal setting intervention on first-year college students at a European business school. Students participating in this study were asked to formulate goals about what they would like to improve, learn, and achieve career-wise, among other things. They were also asked to outline strategies for goal attainment and make public statements about their goals. The researchers find that their goal setting intervention positively impacted credits earned as well as retention rate. They also found that the intervention had the most impact on ethnic minority males.

The study conducted by Clark et. al. (2016) comes closest to ours. In two "field experiments" conducted in consecutive semesters, the researchers analyze the effect of performance-based versus taskbased goals on student performance. They find no significant impact of performance-based goals but find that task-based goals positively impact student performance.

Our "lab experiments" with smaller class sizes produce qualitatively similar results as the study by Clark et. al. for performance-based goals. In our first-stage study conducted in Spring 2016, we asked students to set target scores for upcoming tests. We found no significant difference in test performance between treatment and control groups in this performance-based goal experiment. In our second-stage study in Spring 2017, we conducted an actions-based goal experiment wherein we asked students to set target scores along with a set of actions they would take to attain those target scores. Our experiment differs in design from the Clark et. al. (2016) study but produces remarkably different results. Accordingly, we first discuss the differences in our experimental design.

A major difference in experiment design is the goals that students set in the task-based component of our experiments. (In the performance-based rounds, our designs are similar. Our students set target course grade as well as target exam scores; in Clark et. al. (2016), some students set goals for their letter grade in the course while others set goals for exam scores.) Students participating in our action-based goals experiment set the same performance goals as those in the performance-based round and, in addition, listed actions they would take to attain those goals. In the task-based component of the Clark et. al. (2016) experiment, students set goals for tasks but not for performance. This results in a difference in the outcomes that the two studies analyze for the task-based experiment. Clark et. al. (2016) analyzes task completion; it finds that task completion positively impacts performance, but the analysis does not provide direct evidence of whether students' own performance targets are attained. Our study design, by 
contrast, cannot measure task completion; we can, however, measure the impact of goal-setting on performance and, in addition, the attainment of self-set performance targets.

Our study also differs from that of Clark et. al. (2016) in the tasks (actions) that students complete (take). In the Clark et. al. (2016) study, the tasks are extrinsic and are provided to the student: up to five practice tests that they can take in preparation for each exam. By contrast, our study seeks to intrinsically motivate students. Students in our experiment are asked to self-select and record the actions they will take to attain their target grade (score). A list of actions that students said they would take is presented below.

- Attend / pay attention in class / ask questions if required

- Complete homework and all other assignments

- Study / review for exams

- Get extra help when necessary / attend tutoring sessions

- Read course material outside of class / take notes while reading

- Take an actual interest in the material

We note that attending class tops the list, followed by completing homework as scheduled, and studying (reviewing) for quizzes and exams. To the extent we can match performance to a set of stated actions, we are able to identify actions most correlated with target attainment. This advances the literature, albeit in a limited extent, in the direction (also) pointed out by Clark et. al. (2016): "it would be interesting to examine the effects of self-set goals for other tasks such as attending class ...or working through textbook chapters" (Clark, et. al., 2016, p. 32).

The most significant attribute of our study that distinguishes itself from previous literature is the recognition and capture of the intertemporal dynamics of goal-setting and goal-attainment in a setting where students can revise subsequent goals based on prior performance. Most studies analyze the "static" impact of goals set either at the beginning or mid-semester, on course performance at the end of the semester. Students in our study, by contrast, can revise their targets for subsequent exams as the semester progresses, based on their performance on previous exams (it is possible that students also factor in the difficulty level of the material covered on each exam). Consequently, the snapshots of their performance at different points in the semester enable us to study not only the impact of goal setting but also of goal revision. The end result is a richer story about the interaction between goal setting, goal revision, and target attainment.

The dynamic evolution of the experiment and the complexity of capturing its possible effects is illustrated in Figure 1 below using a decision-and-outcome tree diagram. Students set targets and actions, but whether they put in effort or indulge, is either unobservable or can only be observed to a limited extent. What is observable, when they take their first exam, is whether they have attained their target. Prior to the subsequent exam, they set targets and actions again. At this point, they can revise their targets (and actions) if they so choose. If they do revise their target, the reason for doing so is not recorded, ie. students are not asked why they are upgrading or downgrading their target. The process is repeated before each exam. This dynamic environment gives us the ability to analyze whether subsequent performance is related to prior target attainment as well as to target revision. This sets our study apart from all previous empirical studies and is a major contribution to the existing literature. 


\section{THE DYNAMIC NATURE OF GOAL SETTING EXPERIMENT WITH GOAL REVISION}

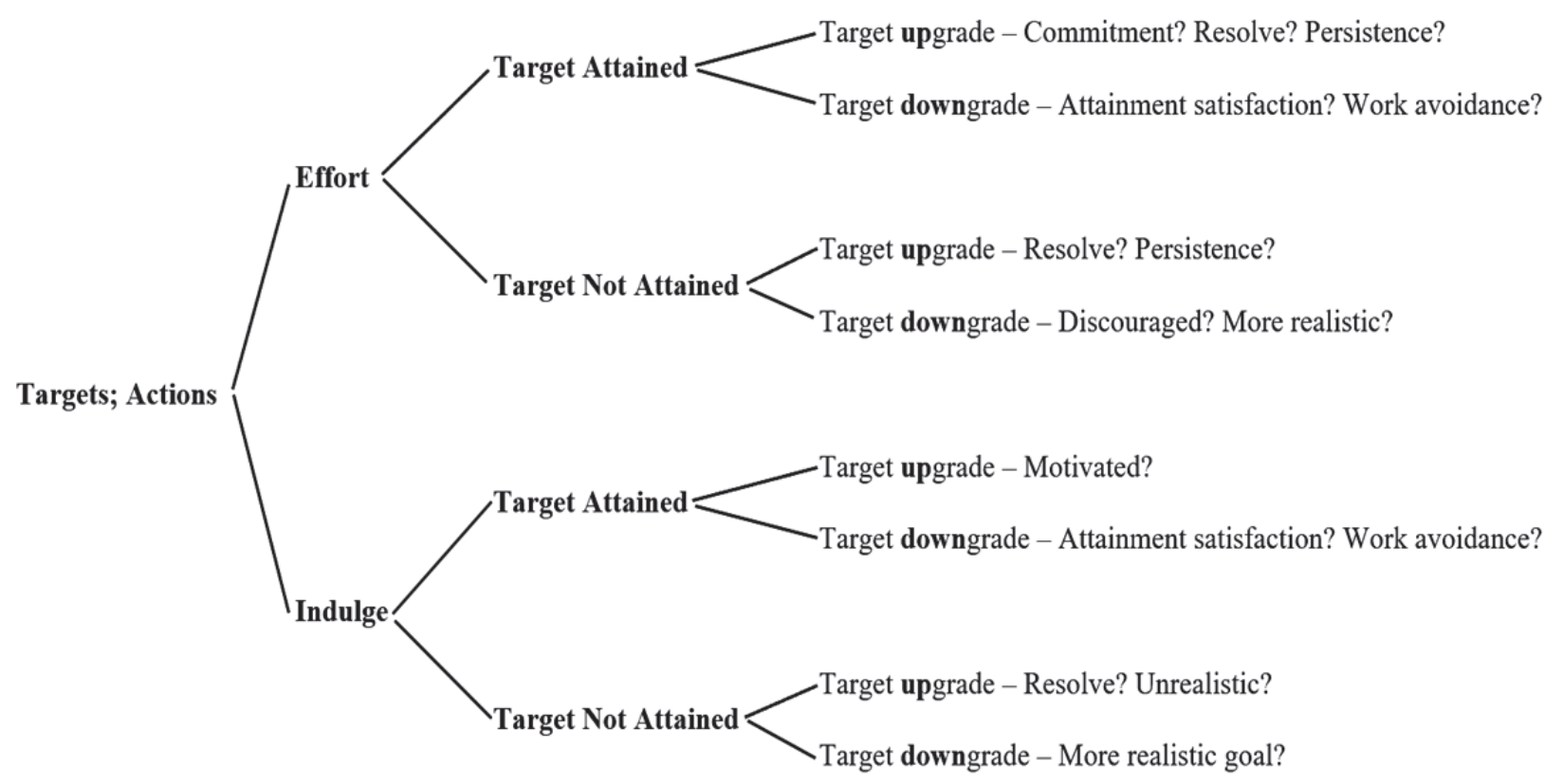

We find that the effect of goal-setting may not be uniform across all students. Indeed, we find that the impact differs between attainers and non-attainers, and between those who choose to upgrade their target versus those that revise their target downward. Further, allowing for a gap period between the second and third exams - when students were not "required" to set goals and actions - provides us information on whether the impact of self-selected goals is sustained when students are temporarily taken off the goalsetting treatment. By analyzing the impact of goal-setting on each test as well as on overall course performance, we explore additional aspects of goal-setting not addressed directly in earlier studies, viz. is the effect sustained through the semester? When goals are attained, do students subsequently set higher goals? Are goal attainment and goal revision correlated with better performance? Which tasks are most correlated with goal attainment?

It may be noted that neither of the researchers taught any of the courses included in the study. All data were analyzed after the completion of the semester.

The rest of the paper is presented as follows. Methodology is discussed first, followed by results. Finally, conclusions are drawn and possible directions for future research are outlined.

\section{METHODOLOGY (THE EXPERIMENT)}

\section{Performance-based Goals; Spring 2016}

As mentioned earlier, we sought possible evidence of performance-based goals as a motivator. Faculty members who taught at least two sections of their courses and were willing, participated in the first round of the study. Three different subject areas were represented in the experiment. The control and treatment groups (sections) were chosen by each faculty member. Participating students in the treatment sections were asked to set target scores for each upcoming test. Both target and actual scores for the treatment group were recorded, as were actual scores for the control group. T-tests were conducted on actual scores for control versus treatment groups to detect possible evidence of the impact of goal setting. Paired t-tests using target scores and actual scores for the treatment groups were used to analyze goal attainment. 


\section{Actionable, or Task-based Goals; Spring 2017}

In Spring 2017, we studied the impact of actionable goals. We suspected that the results from the first-stage experiment could be partly attributed to the inherent passive nature of a performance-based goals experiment; accordingly, this time around we had students more actively involved in their goalsetting exercise. Students in the treatment group were now asked to set a target grade for the course at the beginning of the semester. To infuse elements of self-motivation and personal accountability and encourage students to develop success strategies early on, they were also asked to list actions they would take to attain their goal. Instructions specifically required them to start each sentence with "I will ...". Then, to incorporate discipline, self-motivation, and personal accountability, they were asked to set a target score for each upcoming test, also with a list of actions they would take to attain their goal. The intent behind this repeated intervention was to reinforce the value of the exercise if students had found it helpful in the past.

Students in the participating course took three 'unit exams' during the semester. They set goals and actions for the first two exams, followed by a "gap period" for the third exam when they were not "required" to set goals and actions. They set goals and actions again for the fourth and final exam.

As in the first stage study, t-tests are first conducted on actual scores for control versus treatment groups to detect possible evidence of the impact of goal setting. Having found evidence of a positive impact, regression equations are estimated to measure the effect of goal-setting. We find that students did revise their targets as the semester progressed, suggesting that they did not set their goals passively. This enables us to further analyze, using interaction dummies, whether the impact of our intervention differentially impacts attainers versus non-attainers. All computations were done using SPSS.

\section{RESULTS}

\section{Impact of Performance-based Goals}

Since each test covers different material, the set of scores from each test was treated as a different sample. Combined, results from eight different tests taken by over 100 students in four courses were analyzed. Class sizes ranged from 12 to 26 . We used t-tests to compare means between treatment and control groups to test for possible motivating effect of performance-goal-setting. Paired t-tests were conducted between actual and target scores to look for evidence of goal attainment. A representative set of results for one test in the largest section is presented in Table 1 below. The results are qualitatively similar on every test, for all pairs of course sections participating in the study.

TABLE 1

RESULTS FOR DIFFERENCES IN MEANS (T-TESTS)

\begin{tabular}{|l|l|l|l|l|}
\hline & \multicolumn{2}{|c|}{ Control versus Treatment } & \multicolumn{2}{c|}{ Actual versus Target } \\
\hline & Control & $\underline{\text { Treatment }}$ & $\underline{\text { Actual }}$ & Target \\
\hline Mean & 76.86 & 80.77 & 80.77 & 86.33 \\
\hline Std. deviation & 11.31 & 11.59 & 11.59 & 7.99 \\
\hline $\mathrm{n}$ & 26 & 24 & 24 & 24 \\
\hline & $\mathrm{p}$-value (two-tail) & 0.23 & p-value (one-tail) & 0.0065 \\
\hline Note: Paired t-test for Actual vs. Target \\
\hline
\end{tabular}

Our findings and interpretation can be summarized as follows:

1. Average test scores for the treatment groups were not significantly different from those in the control groups. This suggests that goal setting, in and of itself, does not act as a motivator for a significantly better performance. 
2. Target scores were, in general, significantly higher than actual scores for the treatment groups. Furthermore, actual scores were more variable than target scores. We interpret this result as indicative of low (or no) goal attainment.

Our finding that performance-based goals do not result in better performance is qualitatively similar to that of Clark et. al. (2016) who also find no significant impact of performance-based goals. This is remarkable considering how different the two studies are in terms of sample size and delivery format. The findings of Clark et. al. (2016) are based on "field experiments" with sample sizes of approximately 2,000 students in each round of the experiment, in an online course. Ours is a "lab experiment" involving small class sizes, and our participating courses were all taught face-to-face. Yet the two studies yield the same finding of no significant impact of performance-based goals, perhaps indicative of how remarkably similar students inherently are. The finding can be attributed to a possible passivity when students are merely asked to set goals, with no personal accountability for how they would attain those goals.

\section{Impact of Action-based Goals}

The experiment design in the second stage of the study incorporated action-based goals.

Our analysis excludes students for whom grade point average (GPA) figures were not available, and those in the treatment group who had not set goals for all four exams. This leaves us with a sample size of 19 students in the control group and 17 in the treatment group.

Table 2 presents descriptive statistics for GPA and overall hours completed. there is no significant difference in either average GPA or the average number of hours completed for the treatment and control groups. To the extent that overall GPA is indicative of competence and / or ability, and hours earned measures preparedness and /or maturity, both treatment and control sections seem comparable at the start of the experiment.

TABLE 2

COMPARISON OF CONTROL AND TREATMENT GROUPS

\begin{tabular}{|l|l|l|l|l|}
\hline & \multicolumn{2}{|c|}{ Grade Point Average (GPA) } & \multicolumn{2}{c|}{ Hours earned } \\
\hline & Control & Treatment & Control & Treatment \\
\hline $\mathrm{n}$ & 19 & 17 & 19 & 17 \\
\hline Average & 3.02 & 3.12 & 52.8 & 55.1 \\
\hline Standard deviation & 0.523 & 0.602 & 40.92 & 33.93 \\
\hline Maximum & 3.81 & 4.0 & 138 & 123 \\
\hline Minimum & 2.06 & 1.61 & 16 & 14 \\
\hline Note: Neither average & GPA nor hours earned differed significantly between the two groups \\
\hline
\end{tabular}

Students took four 100-point exams during the semester, each covering a unit of material. For each unit, students also completed homework (varying between 16 to 24 points) and a 10-point quiz. Overall course score is calculated as a simple average of the total points possible.

Table 3 below presents average and standard deviation for each of the four exams. 
TABLE 3

SNAPSHOT OF PERFORMANCE OF CONTROL AND TREATMENT GROUPS

\begin{tabular}{|c|c|c|c|c|c|c|c|c|}
\hline & \multicolumn{2}{|c|}{ Exam 1} & \multicolumn{2}{|c|}{ Exam 2} & \multicolumn{2}{|c|}{ Exam $3^{+}$} & \multicolumn{2}{|c|}{ Exam 4} \\
\hline & Treat & Ctrl & Treat & Ctrl & Treat & $\mathrm{Ctrl}$ & Treat & Ctrl \\
\hline Average & 90.76 & 85.53 & 87.94 & 85.53 & 80.71 & 73.84 & 87.82 & 85.53 \\
\hline Std. dev & 5.96 & 7.49 & 10.15 & 8.89 & 15.96 & 12.17 & 10.01 & 7.43 \\
\hline $\mathrm{CoV}$ & 6.57 & 8.75 & 11.54 & 10.40 & 19.78 & 16.58 & 11.40 & 8.68 \\
\hline t-stat & \multicolumn{2}{|c|}{$2.30 * *$} & \multicolumn{2}{|c|}{0.76} & \multicolumn{2}{|c|}{$1.46^{*}$} & \multicolumn{2}{|c|}{0.79} \\
\hline \multicolumn{9}{|c|}{$\begin{array}{l}\text { Note: "Treat" denotes Treatment group and "Ctrl" denotes Control group } \\
\text { ** denotes significance at } 5 \% \text { and } * \text { at } 10 \% \\
+ \text { Students were not required to set a target for this exam. }\end{array}$} \\
\hline
\end{tabular}

The following observations are noteworthy:

- The treatment group has a higher average on every exam, including Exam 3 for which they were not required to set any targets or actions;

- The average score for the treatment group is statistically higher on Exams 1 and 3;

- Exam scores for the treatment group are more variable than those for the control group on all exams except the first.

In the rest of this section, we explore the following questions:

i. Do students follow up on the action most frequently selected - attendance?

ii. What is the target attainment rate? Once a target is attained, do students revise their targets?

iii. Does goal setting deliver, ie. do students who set actionable goals also perform better? If yes, is the impact sustained, especially through a gap period? Is performance correlated with goal attainment and/or goal revision?

iv. Which actions are most correlated with target attainment?

v. What is the evidence on overall course score and course grade target attainment?

\section{Action Completion - the Evidence on Attendance}

We noted earlier that attending class regularly was the most frequently mentioned action on students' action list. If students took the goal setting exercise seriously and followed up on their actions, we expect to see better attendance in the treatment group compared to the control group. Table 4 presents regression results for attendance in each of the four segments into which the course is divided. Attend 1 is the number of days a student attended class in the weeks leading up to Exam 1, Attend 2 the number of days attended between Exams 1 and 2, and so on. 
TABLE 4

RESULTS FOR ACTION COMPLETION

\begin{tabular}{|c|c|c|c|c|c|c|c|c|}
\hline Dependent $\longrightarrow$ & & end 1 & & nd 2 & & id $3^{+}$ & & ad 4 \\
\hline & Coeff & t-ratio & Coeff & t-ratio & Coeff & t-ratio & Coeff & t-ratio \\
\hline Intercept & 5.12 & $7.37 * *$ & 4.77 & $7.23 * *$ & 2.26 & $2.31 * *$ & 0.90 & 1.12 \\
\hline GPA & 0.44 & $1.95 *$ & 0.55 & $2.57 * *$ & 0.78 & $2.45^{* *}$ & 1.03 & $3.93 * *$ \\
\hline Goal Dummy & 0.53 & $2.17 * *$ & 0.36 & 1.53 & 0.72 & $2.06^{* *}$ & 0.18 & 0.62 \\
\hline Gender Dummy & -0.64 & $-2.49 * *$ & -0.36 & -1.46 & -0.56 & -1.53 & -0.16 & -0.54 \\
\hline & Adj. $R^{2}$ & $=0.257$ & Adj. $R^{2}$ & 0.195 & Adj. R & 0.229 & Adj. R & 0.280 \\
\hline & $\mathrm{n}=36$ & & $\mathrm{n}=36$ & & $\mathrm{n}=36$ & & $\mathrm{n}=36$ & \\
\hline $\begin{array}{l}\text { "Attend" is the n } \\
\text { "Goal Dummy" } \\
\text { "Gender Dummy } \\
\text { ** denotes signifi } \\
+ \text { Students were } \\
\end{array}$ & $\begin{array}{l}\text { er of } \\
\text { the } v \\
1 \text { for } \\
\text { ce at } \\
\text { equir }\end{array}$ & $\begin{array}{l}\text { male stu } \\
\text { and } * \\
\text { to set a }\end{array}$ & $\begin{array}{l}\text { etween } \\
\text { dents }\end{array}$ & $\begin{array}{l}\text { exan } \\
\text { e trec }\end{array}$ & $g r$ & & & \\
\hline
\end{tabular}

Attendance is strongly correlated with overall GPA, providing evidence that students' attitudes towards attending class are well developed by the time they enroll for this course. A slightly unexpected result is that female students attend class less regularly than their male counterparts. The encouraging sign is that the difference is not significant beyond the first unit.

The goal dummy is positive in all four units of the course, indicating that students who set goals attend class more than their non-goal-setting counterparts. The parameter alternates in statistical significance, however, between the four units of the course. The lack of significance in units 2 and 4 can possibly be attributed to goal attainment satisfaction on the preceding two units, something we explore a little later in this section.

\section{Evidence on Goal Attainment and Target Revision}

In our experiment, students set a target grade for the course and target numerical scores for each test. Accordingly, we present two different target attainment measures for test scores. The first measure (M1) strictly compares numerical values of target and actual scores, ie. the performance goal is said to have been attained if a student's actual score is at least as high as her target score. For the second measure (M2), we note that a student's actual score may be numerically lower than her target score but still within the same letter grade (for example, a student who set a target of 95 but scored 90). We consider a target attained if the student's actual score is in the same conventional letter grade as her target. Evidence of target attainment is presented in Table 5 below.

TABLE 5

EVIDENCE OF GOAL ATTAINMENT

\begin{tabular}{|l|c|c|c|}
\hline & Exam 1 & Exam 2 & Exam 4 \\
\hline M1 & $62.5 \%$ & $62.5 \%$ & $41.2 \%$ \\
\hline M2 & $75.0 \%$ & $75.0 \%$ & $58.8 \%$ \\
\hline Note: Students were not required to set targets for Exam 3 \\
\hline
\end{tabular}

The proportion of students attaining their target scores is over 60 percent on Exams 1 and 2 using the M1 measure, and 75 per cent using the M2 measure.

With over 60 per cent of students attaining their stated target score on Exam 1, how were targets for Exam 2 revised? For this, we report proportions using only the M1 measure since some students are 
found to set subsequent targets that are numerically higher (or lower) but within the same letter grade. We find that 66.67 per cent of those who had attained their target on Exam 1, set a higher target for Exam 2 (33.3 per cent revised their target downward). Of those who had not attained their target, 83.3 per cent upgraded their Exam 2 target while only 16.7 per cent downgraded. To the extent upgrades reflect students' resolve to perform better, we expect this to reflect on their actual performance. On the other hand, if revising scores downward is reflective of either goal attainment satisfaction or more realistic target setting, this may subsequently reflect in lower actual performance. Interestingly, this difference in attitude may have a long-lasting influence; something we comment on in the next subset of results.

We also note the strikingly low attainment level for Exam 4 compared to the high attainment levels for Exams 1 and 2. This evidence seems to corroborate our earlier suggested interpretation that, having attained their target scores on previous exams and reasonably sure they could maintain their target grade for the course, students in the treatment group may either have passively completed the goal-setting exercise at this point in the semester, and / or not considered it important to attain this final goal.

\section{Evidence of the Effect of Action-Based Goals on Performance}

The primary research question for this study is whether actions-based goal-setting can lead to better student performance. Table 6 presents our estimated regression equations. For the first exam of the semester, we include only GPA, along with goal and gender dummies, as independent variables. When prior exam scores become available, students have a chance to incorporate this information to revise their subsequent goals and actions. Accordingly, on subsequent exams, we include the previous exam score and interaction terms to capture the effects of goal attainment and goal revision. Inclusion of previous score as well as attainment variables, captures the dynamic nature of the experiment.

The following is the story we can tell based on our most informative equation specifications:

- Goal setting has a positive impact on students' performance on the first three exams;

- The nature of the impact varies by exam. On the first two exams, we see a significant positive level impact. Goal-setting adds an average of 5 points to a student's score on Exam 1 and about 8 points on Exam 2;

- On Exam 2, a slope effect is also detected; the correlation between Exam 1 and 2 scores seems to also depend on whether a student had attained her/his goal on Exam 1.

- For students who had set a goal, performance on Exam 3 is significantly different between those who had upgraded their targets for Exam 2 versus those who had not. Those who had upgraded their targets performed better than the control group, while those who had downgraded performed worse.

- There is no perceptible impact of goal setting on performance on Exam 4 when Exam 3 is included as an explanatory variable. Other specifications including interaction terms produced qualitatively similar results.

- Exam 4 scores are better correlated with Exam 2 scores than with Exam 3 scores. An alternate specification with Exam 2 score as an explanatory variable and interaction terms for target 4 upgrade (downgrade) with Exam 2 score, shows weak impact of goal-setting on target upgraders.

- Combined, the results for Exam 4 suggest that either (a) the novelty of goal-setting wore off as the semester wound down, or (b) overall course targets were met by this time, resulting in "mean-reverting behavior" in the treatment group, or (c) once students were reasonably sure they would attain their target grade in the course, they adopted a work avoidance approach $(a$ la Barron \& Harackiewicz, 2003). 
TABLE 6

IMPACT OF GOAL-SETTING ON PERFORMANCE

\begin{tabular}{|c|c|c|c|c|c|c|c|c|}
\hline \multirow[t]{2}{*}{ Dependent $\longrightarrow$} & \multicolumn{2}{|c|}{ Exam 1 } & \multicolumn{2}{|c|}{ Exam 2} & \multicolumn{2}{|c|}{ Exam $3^{+}$} & \multicolumn{2}{|c|}{ Exam 4} \\
\hline & Coeff & t-ratio & Coeff & t-ratio & Coeff & t-ratio & Coeff & t-ratio \\
\hline Intercept & 73.09 & $12.51 * *$ & 13.19 & 0.76 & -10.19 & -0.65 & 46.00 & $7.06 * *$ \\
\hline GPA & 3.53 & $1.86^{*}$ & 6.36 & $2.52 * *$ & 7.15 & $2.04 *$ & 10.16 & $4.85 * *$ \\
\hline Goal Dummy & 5.33 & $2.56^{* *}$ & 8.11 & $1.76^{*}$ & & & -0.20 & -0.09 \\
\hline Gender Dummy & 4.74 & $2.19 * *$ & -5.73 & $-1.98^{*}$ & 0.81 & 0.23 & 0.15 & 0.07 \\
\hline Previous Exam & & & 0.64 & $2.97 * *$ & 0.73 & $3.48 * *$ & 0.12 & 1.45 \\
\hline E1AI & & & -0.11 & $-2.18^{*}$ & & & & \\
\hline E1NAI & & & -0.08 & -1.16 & & & & \\
\hline Target up & & & & & 8.73 & $2.28 * *$ & & \\
\hline Target down & & & & & -11.13 & $-2.04 * *$ & & \\
\hline & \multicolumn{2}{|c|}{ Adj. $\mathrm{R}^{2}=0.275$} & \multicolumn{2}{|c|}{ Adj. $\mathrm{R}^{2}=0.408$} & \multicolumn{2}{|c|}{ Adj. $R^{2}=0.536$} & \multicolumn{2}{|c|}{ Adj. $\mathrm{R}^{2}=0.531$} \\
\hline & \multicolumn{2}{|c|}{$\mathrm{F}=5.425 * *$} & \multicolumn{2}{|c|}{$\mathrm{F}=5.027 * *$} & \multicolumn{2}{|c|}{$\mathrm{F}=9.102 * *$} & \multicolumn{2}{|c|}{$\mathrm{F}=10.922 * *$} \\
\hline & \multicolumn{2}{|c|}{$\mathrm{n}=36$} & \multicolumn{2}{|c|}{$\mathrm{n}=36$} & \multicolumn{2}{|c|}{$\mathrm{n}=36$} & \multicolumn{2}{|l|}{$\mathrm{n}=36$} \\
\hline \multicolumn{9}{|c|}{$\begin{array}{l}\text { Gender Dummy takes the value } 1 \text { for female students. } \\
\text { "Previous Exam" is the score on the previous exam. } \\
\text { E1A and E1NA are dummies to identify target Attained and Not Attained. } \\
\text { E1AI and E1NAI are interaction variables with Exam } 1 \text { score. } \\
\text { Target up denotes target } 2>\text { target } 1 ; \text { Target down denotes target } 2<\text { target } 1 \text {. } \\
* * \text { denotes significance at } 5 \% \text { and } * \text { at } 10 \% \text {; } \\
+ \text { Students were not required to set a target for this exam. }\end{array}$} \\
\hline
\end{tabular}

Our findings offer interesting insight into how goal setting impacts students. There was a gap period when students were not required to set a target for Exam 3; yet students who had upgraded their targets for Exam 2 performed better than those who had downgraded their target. Our analysis of attendance, presented earlier, had revealed that attendance in the third unit of the course is statistically higher for the treatment group than the control group though this was a gap period. Together, these results would suggest that the behavioral changes attributable to participation in the goal setting exercise has a lasting impact on students.

On the other hand, performance of students who downgraded their Exam 2 target is found to be significantly weaker than the control group of students. Does this suggest satisfaction with target attainment on Exam 1? Recall that about a third of target attainers had downgraded their targets for Exam 2. Or, do some students get disillusioned when they are unable to attain their target, and respond either by lowering their target or by passively completing the exercise while not following up on their action list? Future research can shed light on this question.

\section{Actions Most Cited by Target Attainers}

At an earlier point, we documented evidence of significant attendance differential between students who set targets and those that did not. Students had listed other actions they would take to attain their target, some of which were listed before. We conducted a mapping from attainers to actions, in an attempt to identify the most effective success strategies. We hope that this information will be helpful for students, educators, and / or advisors interested in doing their own goal-setting experiments.

The following are some actions the high attainers had stated at the beginning of the semester:

- Read assigned material before class,

- Attend class regularly (this was by far the most often stated action),

- Follow up with reading after class,

- Study a little at a time instead of studying just before an exam, 
- Attend tutoring sessions if required.

The high achievers in our study also consistently stated before each exam that they would:

- Study ahead of time, and

- Review notes and homework.

\section{Evidence on Overall Course Score and Course Grade Attainment}

We also analyzed the impact that the goal setting experiment had on overall course score and target grade attainment. Regression results show no significant impact of goal setting on overall course score (neither dummy nor interaction terms are significant in various alternative specifications of the model). While this may seem counter-intuitive, it is important to note that overall course score was a simple average of exam, quiz, and homework scores. We analyzed quiz and homework scores in search of a possible explanation. Compared to their classmates in the control group, we found that students in the treatment group neither have significantly better homework scores nor significantly higher quiz scores. In addition, we saw earlier that the treatment group performed significantly better on the first exam. Beyond that, however, the impact is different on attainers versus non-attainers, and between those who reach higher (upgrade) versus lower (downgrade). Our finding that overall course score is not significantly higher for the treatment group could therefore be attributable to the lack of a significant difference in the underlying components of overall course average.

Finally, only 44 per cent students attained the target grade they had set for themselves at the beginning of the semester.

\section{CONCLUSION}

Can goal-setting motivate college-level students to perform better in their courses? We conducted a two-stage study to test the effects of performance-based versus actionable goals. We found that performance-based goals do not act as significant motivators but action-based goals do, albeit to a limited extent. The overall story that emerges is of an initial spike in performance followed by different performance trajectories for attainers versus non-attainers, and an eventual convergence to the "normal" level.

Despite the obvious limitations imposed by its small sample size, our study makes at least three important contributions to the research on goal setting in educational institutions. First, it shows that college level students have the maturity to self-select actions that will help them attain their goals. This finding is important if educators indeed strive to teach students how to become life-long learners and find intrinsic motivation. Second, we provide evidence suggesting a two-way interaction between goal setting, goal attainment, and goal revision. The attainment trajectories for attainers are different than for nonattainers, and for those who upgrade their targets versus those that downgrade. For students seeking optimal allocation of study time to multiple courses, our finding suggests that a strong early start can provide opportunity for a relaxed experience later. Third, we provide some evidence that positive attitudinal changes resulting from a goal-setting exercise can have a lasting impact on students. At a time when educational institutions are constantly seeking ways to impact performance in a budget-friendly and scalable manner, our findings may be of interest to educators and administrators alike. Our findings should be especially interesting for community colleges that suffer from low retention and success rates.

At the same time, our results also suggest that goal-setting must be used with caution, since it can discourage some students who do not attain their targets. Does this mean goal-setting is not beneficial and should not be implemented? We believe such inference would be akin to throwing the baby out with the bathwater. Rather, a targeted goal-setting intervention may be especially useful for at-risk students. Early alert programs are used at many institutions to identify weak performers early on and initiate some intervention to help them succeed. Our findings suggest that putting students on a "treatment plan" that includes actions-based goal-setting may be beneficial, in addition to tutorial support that is a core component of most early alert programs. Regular meetings with these students to ensure they are 
following up on their action plans, and helping them see the correlation between actions and performance, may provide these students with a life-long learning skill.

In future research, a promising approach would be to study what kind of externalities a goal-setting exercise can generate. Do students benefitting from a goal-setting exercise in one course, also set explicit goals and actions for other courses they are enrolled in? Is there a positive spillover effect in that these students then distribute their time and effort to perform equally well in all courses? Or, do students substitute effort in other courses to attain their "revealed" targets in the course conducting the experiment, resulting in a negative externality?

Likewise, it would be interesting to follow students through their entire college career to see whether they continue to use goal-setting for success. This can be done by encouraging goal setting as a success strategy during freshman orientation and then tracking students' performance through graduation.

Finally, from an econometrics perspective, it would be interesting to explore panel data specifications with larger class sizes.

Our research has merely scratched the surface of an important topic in education - improving student success. Student populations can be remarkably different at different institutions. Success strategies that work in one course, or even at one institution, may not necessarily work in another. Yet, research conducted in different settings informs our collective understanding of what motivates students and helps them succeed. We hope the results of our "lab experiment" will trigger similar initiatives at other institutions.

\section{ACKNOWLEDGMENTS}

This paper has benefited from comments and feedback received at the Illinois Economic Association Conference, 2017 and the Conference on Teaching and Research in Economic Education, 2018 where it

was presented. We thank all faculty who participated in the experiment, without whom this study would not have been feasible. 


\section{REFERENCES}

Barron, K. E., \& Harackiewicz, J. M. (2003). Revisiting the benefits of performance-approach goals in the college classroom: Exploring the role of goals in advanced college courses. International Journal of Educational Research, 39(4), 357-374.

Barron, K. E., \& Harackiewicz, J. M. (2001). Achievement goals and optimal motivation: Testing multiple goal models. Journal of Personality and Social Psychology, 80, 706-722.

Clark, D., Gill, D., Prowse, V. L., \& Rush, M. (2016). Using Goals to Motivate College Students: Theory and Evidence from Field Experiments. NBER Working Paper No. w23638. Retrieved from https://ssrn.com/abstract $=3011137$

Hamilton, J., \& Tee, S. (2013). Blended teaching and learning: a two-way systems approach, Higher Education Research \& Development, 32(5), 748-764. DOI: 10.1080/07294360.2012.711301

Jalava, N., Joensen, J. S., \& Pellas, E. (2014). Grades and Rank: Impacts of Non-Financial Incentives on Test Performance. IZA Discussion Paper No. 8412. Retrieved from http://ssrn.com/abstract=2492439

Levitt, S. D., List, J. A., Neckermann, S., \& Sadoff, S. (2012). The behavioralist goes to school: Leveraging behavioral economics to improve educational performance. NBER Working Paper No. 18165. Available at https://ssrn.com/abstract $=2085152$

Locke, E., \& Latham, G. (1990). A Theory of Goal Setting and Task Performance. Prentice Hall Englewood Cliffs, NJ.

Schippers, M.C., Scheepers, A. W. A., \& Peterson, J. B. (2015). A Scalable Goal-Setting Intervention Closes Both the Gender and Ethnic Minority Achievement Gap. Palgrave Communications 1, 15014(2015). Retrieved from http://www.palgrave-journals.com/articles/palcomms201514\#di

Shinaberger, L. (2017) Components of a Flipped Classroom Influencing Student Success in an Undergraduate Business Statistics Course. Journal of Statistics Education, 25(3), 122-130. DOI: $10.1080 / 10691898.2017 .1381056$

Suvorov, A., \& J. van de Ven (2009). Goal-Setting as a Self-Regulation Mechanism. Retrieved from http://ssrn.com/abstract=1286029

Winquist, J. R., \& Carlson, K. A. (2014). Flipped Statistics Class Results: Better Performance Than Lecture Over One Year Later. Journal of Statistics Education, 22(3). DOI:

https://doi.org/10.1080/10691898.2014.11889717 